Portland State University

PDXScholar

Environmental Science and Management

Faculty Publications and Presentations

\title{
Complex Interactions Between Regional Dispersal of Native Taxa and an Invasive Species
}

\author{
Angela L. Strecker \\ Portland State University, angela.strecker@wwu.edu \\ Shelley E. Arnott \\ Queen's University - Kingston, Ontario
}

Follow this and additional works at: https://pdxscholar.library.pdx.edu/esm_fac

Part of the Ecology and Evolutionary Biology Commons, and the Environmental Sciences Commons Let us know how access to this document benefits you.

\section{Citation Details}

Strecker, A. L., \& Arnott, S. E. (2010). Complex interactions between regional dispersal of native taxa and an invasive species. Ecology, 91(4), 1035-1047

This Article is brought to you for free and open access. It has been accepted for inclusion in Environmental Science and Management Faculty Publications and Presentations by an authorized administrator of PDXScholar. Please contact us if we can make this document more accessible: pdxscholar@pdx.edu. 


\title{
Complex interactions between regional dispersal of native taxa and an invasive species
}

\author{
Angela L. Strecker ${ }^{1}$ and Shelley E. Arnott \\ Department of Biology, Queen's University, Kingston, Ontario K7L 3 N6 Canada
}

\begin{abstract}
In the event of an environmental disturbance, dispersal of native taxa may provide species and genetic diversity to ecosystems, increasing the likelihood that there will be species and genotypes present that are less vulnerable to the disturbance. This may allow communities to maintain functioning during a disturbance and may be particularly important when the perturbation is novel to the system, such as the establishment of an invasive species. We examined how dispersal of native species may influence crustacean zooplankton communities in freshwater lakes invaded by the invertebrate predator, Bythotrephes longimanus. Using large enclosures, we experimentally tested the effect of dispersal on zooplankton community abundance, richness, and composition in (1) a community invaded by Bythotrephes, (2) the same community with the invader removed, and (3) a community that was never invaded. Dispersal increased zooplankton community abundance and richness; however, these effects were usually only significant in the invader-removed treatment. Dispersal tended to make the invader-removed communities more similar to never-invaded communities in abundance, richness, and composition. Dispersal had little effect on zooplankton abundance in the invaded community; however, richness significantly increased, and the community composition changed to resemble a never-invaded community by the end of the experiment. Our results have implications for understanding the role of dispersal during transitory states in communities. Dispersal of native taxa may be particularly important during the period between the arrival and broad-scale establishment of Bythotrephes, as dispersal through space or time (i.e., from resting eggs) may rapidly increase zooplankton abundance when the invader is absent or in low abundances. Overall, our results suggest that communities with strong local predatory and competitive interactions may be closed to immigration from colonists, but that invasive species may alter the conditions under which species can establish. These results have implications for the interaction of native and invasive species across broad spatial scales, as regional dispersal of native taxa may forestall the local extirpation of native species. In particular, transient phases that result from variable persistence of invaders within habitats or across a region may permit native colonists to successfully establish, and thus increase local and regional resistance to future disturbance.
\end{abstract}

Key words: Bythotrephes longimanus; crustacean zooplankton; dispersal; freshwater lakes; invasive species; metacommunity; predation; transient dynamics.

\section{INTRODUCTION}

Since the publication of the landmark theory of island biogeography (MacArthur and Wilson 1967), dispersal has received increasing attention for its role in influencing the biodiversity of ecosystems (Brown and KodricBrown 1977, Holt 1985, Shmida and Wilson 1985, Holyoak et al. 2005). Meta-analyses have indicated that dispersal can increase species richness and alter community composition in a variety of terrestrial and aquatic habitats (Cottenie 2005, Cadotte 2006). However, the relative influence of local (e.g., interspecific interactions) vs. regional (e.g., dispersal) factors on

Manuscript received 10 January 2008; revised 22 May 2009; accepted 30 June 2009. Corresponding Editor: K. L. Cottingham.

${ }^{1}$ Present address: School of Aquatic and Fishery Sciences, University of Washington, Seattle, Washington 98105 USA.

E-mail: angelast@u.washington.edu community structure and composition remains poorly understood. Cornell and Lawton (1992) suggested that communities were rarely saturated with species, indicating that dispersal limits the composition of communities. While some empirical studies have supported the assertion that dispersal is limiting (Shurin et al. 2000, Gilbert and Lechowicz 2004), others have found that the local community prevented establishment of dispersing species (Shurin 2000, Forrest and Arnott 2006). Further studies have demonstrated that dispersal and local interactions can have equally important roles in structuring communities (Tilman 1997). Thus, it is apparent that communities differ in their openness to colonization by new species, suggesting that the importance of dispersal may be determined by a combination of factors including local environmental conditions and the composition of the community itself. 
Theoretical work has shown that during periods of environmental variability immigration can increase abundance of local sink populations (Gonzalez and Holt 2002); thus, dispersal may be particularly important during environmental perturbations (Chesson and Huntly 1997, Chesson 2000, Davis et al. 2000). The introduction of predators to a system can be a major perturbation, with the potential to dramatically alter local communities. Predators can allow inferior competitors to coexist with dominant species (Paine 1966), but this relationship varies with local conditions and interactions between predators and prey (McPeek 1998, Proulx and Mazumder 1998). Additionally, predation can generate resource fluctuations and alter resource availability (Chesson and Huntly 1997), which can favor the establishment of nonresident species (Davis et al. 2000). Shurin (2001) demonstrated that predation facilitated the establishment of colonists in a metacommunity, increasing prey species richness; however, other studies have shown that metacommunity richness is reduced by predation (Kneitel and Miller 2003, Cadotte et al. 2006).

In an attempt to understand how ecological systems respond to perturbations, theoretical ecologists have traditionally considered equilibrium states and focused on long-term behaviors of systems. Recently, there has been increasing recognition of the importance of shorter-term transient dynamics. Transient dynamics differ from the long-term equilibrium behavior of a system (Hastings 2004). Results obtained from shortterm experiments often differ from results of long-term experiments, suggesting that processes operating at different timescales need to be taken into consideration (Hastings 2004). Transient dynamics may influence species coexistence (Huisman and Weissing 1999, Noonburg and Abrams 2005), and therefore, determine the composition of a community (Warren et al. 2003). Theoretical work has suggested that invasion by a predator may instigate transient dynamics in prey communities, where prey species with high demographic rates decline drastically and subsequently face greater extinction via stochastic or Allee effects, especially those species that are vulnerable to the invading predator (Noonburg and Abrams 2005, Wright 2008). Thus, dispersal of regional colonists may play an important role in influencing local community structure during transient phases, although this has yet to be tested in field experiments.

The invasion of nonnative species is expected to have a large impact on ecosystems, particularly in lakes (Sala et al. 2000). Bythotrephes longimanus Leydig (Cladocera, Cercopagididae) (hereafter Bythotrephes) is a predaceous zooplankter that has invaded all of the North American Great Lakes (Johannsson et al. 1991) and over 100 inland lakes in Ontario and the upper United States (MacIsaac et al. 2004, Branstrator et al. 2006). Bythotrephes feeds on a variety of zooplankton taxa (Vanderploeg et al. 1993), and has substantially reduced crustacean zooplankton species richness and abundance in invaded lakes (Yan et al. 2002, Strecker et al. 2006). In addition, Bythotrephes can reduce epilimnetic secondary production in lakes (Strecker and Arnott 2008), potentially disrupting the flow of energy to higher trophic levels and altering ecosystem function. Bythotrephes is seasonally parthenogenetic, producing sexual resting eggs in the fall that overwinter in lake sediments (Yan et al. 2001). Bythotrephes population dynamics vary both intra- and inter-annually (Young 2008), as does their persistence throughout the summer (Strecker et al. 2006), creating windows of time in which the predator is virtually absent and prey species are released from Bythotrephes predation. Fluctuations in invader populations can occur during the early stages of invasion when Allee effects may slow population growth rates, generating transient crashes in prey species abundance as susceptible taxa become more prone to stochastic extinction (Wright 2008). Thus, transient dynamics may occur at different levels of organization during an invasion: first, at the population-level for the invader during establishment, and second, at the community-level for the prey, as they shift to another state in response to the invader. We will refer to these as transient-invader dynamics and transient-prey responses. In this study, we experimentally manipulated the dynamics of an invasive predator and measured the response of the prey community in the presence and absence of dispersal of native species.

Broadly, our objective was to experimentally determine the importance of dispersal in altering local community structure (abundance, richness, composition) at different phases of the establishment of an invasive species: the stable preinvasion state, and two possible postinvasion outcomes. The first postinvasion outcome is characterized by stable invader abundance and persistence, where the invader is a dominant member of the ecosystem (invaded treatment). The second postinvasion outcome, the transient-invader state, reflects variable persistence of the invader, where the invader fails to become dominant in the system, but may exist in small numbers or possibly become locally extinct (invader-removed treatment). Studies have demonstrated that some established invasive species are only transient members of the community and may become severely reduced or locally extirpated (Warren et al. 2003, Simberloff and Gibbons 2004). Thus, it seems likely that an invader may display different postinvasion outcomes in different systems. Finally, we chose a lake that has never been invaded by Bythotrephes to represent the preinvasion state (never-invaded treatment).

We predicted that dispersal would have the following effects on zooplankton communities with different invader treatments.

1) Invaded. Dispersal will increase abundance and richness of zooplankton by providing new propagules to fill niches made empty by the invader (i.e., the rescue effect; Brown and Kodric-Brown 1977). However, 
colonist establishment will be moderate due to continued predation by Bythotrephes on the newly arrived dispersers (Cadotte et al. 2006), and will likely be restricted to species that can tolerate or avoid predation (Howeth and Leibold 2008).

2) Invader-removed. Dispersal will lead to greater increases in zooplankton abundance and richness, since colonists will be able to fill empty niches created by predation and exploit unused resources (MacArthur and Levins 1967), but will not experience predation by Bythotrephes. Taxa that are vulnerable to Bythotrephes will likely have the greatest establishment success, as they tend to have higher intrinsic growth rates (e.g., cladocerans; Allan and Goulden 1980), and therefore would be most effective at recolonizing a system affected by invasion.

3) Never-invaded. Dispersal will have no effect, as biotic resistance is high and establishment of new organisms would be prevented by effective resource partitioning by the local community (MacArthur and Levins 1967, De Meester et al. 2002).

\section{Materials And Methods}

\section{Experimental design and sampling protocols}

Our experiment was conducted in Killarney Wilderness Park, which is located about $60 \mathrm{~km}$ from Sudbury, Ontario, on the Canadian Shield. The lakes are circumneutral, oligo-mesotrophic, and have similar chemical and physical properties (Appendix A). Three of the lakes were acidified because of regional acid deposition in the 1960s, but have since experienced chemical and biological recovery (Holt and Yan 2003, Keller et al. 2003).

We conducted an enclosure experiment in George Lake, Killarney Park, in July and August 2004. Bythotrephes has been previously observed in George Lake (A. Strecker, unpublished data). Clear plastic enclosures (1 m diameter, $9 \mathrm{~m}$ deep, total volume 7069 L; Filmtech Plastics, Brampton, Ontario, Canada) were suspended between the cross-bars of $15 \mathrm{~m}$ long floating wooden frames. The top of the enclosures was $0.3 \mathrm{~m}$ above the water level to prevent transfer of water and animals between the lake and the enclosures. The enclosures were covered with mesh (5-mm pore size) to prevent aerial zooplankton colonization by macroinvertebrate and waterbird vectors, and were closed at the bottom. Enclosures were filled with $50-\mu \mathrm{m}$ filtered water from George Lake on 5 July 2004. The pH of all of the enclosures was raised from a $\mathrm{pH}$ of approximately 6.4 to pH 6.9 using sodium hydroxide $(\mathrm{NaOH})$ (Fisher Scientific, Pittsburgh, Pennsylvania, USA) to resemble the $\mathrm{pH}$ of zooplankton source lakes and ensure that there was no acid stress for the zooplankton.

We used a $2 \times 3$ factorial design to test our hypotheses. The dispersal treatment had two levels: (1) regional zooplankton dispersers collected from three lakes (Bell, Helen, and Low); and (2) no dispersal, assuming that few zooplankton entered the enclosures aerially. The invasion treatment had three levels: (1) invaded; (2) invader removed; and (3) never invaded. To construct the invaded and invader-removed treatments, we chose an invaded lake (Bernard Lake) for a source of zooplankton prey. Bythotrephes was first detected in Bernard Lake in 1998, and sampling from multiple years suggests that Bythotrephes is a well-established member of the lake fauna (A. Strecker, unpublished data). Zooplankton were collected from Bernard Lake and added to invaded and invader-removed enclosures at ambient density, after removing all Bythotrephes. To create the invaded treatment, Bythotrephes individuals from Bernard Lake were added to enclosures at moderately high densities (11 individuals $/ \mathrm{m}^{3}$, consistent with mid-summer values observed in Harp Lake, Ontario [Yan et al. 2001]). Bythotrephes was maintained at a relatively constant and elevated abundance, simulating the greater persistence and abundance that is observed in some invaded lakes (Strecker et al. 2006). To create the invader-removed treatment, we used the same invaded lake but removed all Bythotrephes for that treatment. To construct the never-invaded treatment, zooplankton were collected from Ishmael Lake and added to enclosures at ambient densities. Each treatment was replicated four times. All of the lakes in the experiment are located in a similar biogeographical region (Sprules 1977).

Zooplankton were collected from Bernard Lake on 6 July with an $80-\mu \mathrm{m}$ mesh conical net (diameter: $0.35 \mathrm{~m}$ ), stored in 20-L plastic carboys for transport to the experiment and added to invaded and invader-removed treatment enclosures at ambient density. Bythotrephes were collected separately with a $400-\mu \mathrm{m}$ mesh conical net (diameter: $0.5 \mathrm{~m}$ ) on the same date, were stored in 20-L carboys for transport to the experiment, and 80 individuals were added to each of the invaded treatment enclosures. A Bythotrephes addition was repeated on 22 July (between weeks 1 and 2) to ensure that the presence of the invader was maintained. Zooplankton were collected from Ishmael Lake on 9 July and added to the never-invaded experimental enclosures following the same procedures as the zooplankton collections from Bernard Lake. Macroinvertebrate predators, including Bythotrephes in the Bernard Lake zooplankton, were removed from collections of both colonists and experimental zooplankton before addition to the enclosures by visually inspecting all zooplankton collections and manually removing individuals with forceps.

Regional dispersers were collected from Low, Helen, and Bell lakes with an $80-\mu \mathrm{m}$ mesh conical net (diameter: $0.15 \mathrm{~m}$ ) on 15 July (between weeks 0 and 1) and 5 August (between weeks 3 and 4). Since natural dispersal levels are difficult to quantify, we chose a level of dispersal $(\sim 1.7 \%$ of the enclosure volume) that was within the range of dispersal rates observed in interconnected ponds (Michels et al. 2001) and has been used in similar experimental manipulations (Kneitel and Miller 2003, Cadotte et al. 2006, Forrest and Arnott 2006). 
TABLE 1. RM-ANOVAs for zooplankton community metrics and functional group abundance.

\begin{tabular}{|c|c|c|c|c|c|c|c|c|c|c|c|}
\hline \multirow[b]{2}{*}{ Effect } & \multirow[b]{2}{*}{$\mathrm{df}$} & \multicolumn{2}{|c|}{ Abundance } & \multicolumn{2}{|c|}{ Richness $\dagger$} & \multicolumn{2}{|c|}{ Similarity $\dagger$} & \multicolumn{2}{|c|}{ Calanoids } & \multicolumn{2}{|c|}{ Cyclopoids } \\
\hline & & $F$ & $P$ & $F$ & $P$ & $F$ & $P$ & $F$ & $P$ & $F$ & $P$ \\
\hline$\overline{I n v}$ & 2,18 & 44.95 & $<0.01$ & 51.78 & $<0.01$ & 139.54 & $<0.01$ & 3.02 & 0.07 & 15.86 & $<0.01$ \\
\hline Disp & 1,18 & 23.86 & $<0.01$ & 12.33 & $<0.01$ & 26.81 & $<0.01$ & 3.56 & 0.08 & 3.62 & 0.07 \\
\hline Inv $\times$ disp & 2,18 & 5.37 & 0.01 & 5.76 & 0.01 & 11.26 & $<0.01$ & 0.39 & 0.68 & 1.43 & 0.27 \\
\hline Time & 4,72 & 5.52 & $<0.01$ & 6.23 & $<0.01$ & 3.56 & 0.02 & 12.01 & $<0.01$ & 10.31 & $<0.01$ \\
\hline Time $x$ inv & 8,72 & 6.20 & $<0.01$ & 21.57 & $<0.01$ & 0.02 & 0.89 & 0.85 & 0.57 & 2.50 & 0.02 \\
\hline Time $\times$ disp & 4,72 & 0.52 & 0.72 & 2.32 & 0.07 & 4.16 & 0.01 & 0.16 & 0.96 & 0.22 & 0.93 \\
\hline Time $x$ inv $\times$ disp & 8,72 & 0.89 & 0.53 & 0.80 & 0.60 & 1.32 & 0.27 & 0.44 & 0.89 & 0.98 & 0.46 \\
\hline
\end{tabular}

Notes: Abbreviations: inv, invasion treatment; disp, dispersal treatment; PC1, principal component 1. RM-ANOVA results for Time $\times$ invasion treatments were adjusted by linear contrast if significant differences existed at week 0 (indicated by boldface type).

$\uparrow$ Invasion treatment significantly different at week 0 .

Regional dispersers were also heat killed in boiling water and added to the no dispersal treatment enclosures at the same density as the dispersal treatment. An additional aliquot was preserved for enumeration and estimation of colonist survival (details in Appendix B).

Enclosures were sampled on week 0 (the day following the addition of zooplankton from Bernard and Ishmael lakes) and then at weekly intervals from week 1 through 5. Dissolved oxygen $\left(\mathrm{O}_{2}\right)$ and temperature profiles were taken every two weeks at 1-m intervals with a YSI Model 95 probe (Yellow Springs, Ohio, USA). Water samples for chlorophyll $a(\operatorname{chl} a)$ and chemistry were taken each week with an integrated tube sampler (inner diameter: $17 \mathrm{~mm}$ ) from the top $8 \mathrm{~m}$ of each enclosure and George Lake (see Appendix $\mathrm{C}$ for methods and results). Zooplankton were sampled every week from each enclosure with an $80-\mu \mathrm{m}$ mesh conical net (diameter: $0.15 \mathrm{~m}$ ) from a depth of $8.5 \mathrm{~m}$ to the surface (see Appendix B for taxonomic information and counting protocols). Any Bythotrephes individuals retrieved in sampling were noted and immediately returned to the enclosure. Species abundance results are presented in Appendix B. Species were aggregated into four coarse functional groups: calanoid copepods, cyclopoid copepods, large cladocerans $(>0.8 \mathrm{~mm})$, and small cladocerans $(<0.8 \mathrm{~mm})$. In order to assess the role of the regional colonist pool in influencing community composition during the experiment, we calculated the similarity between each treatment replicate and the pooled regional colonist samples. This was done by averaging the abundance of species across all colonist samples ( 3 lakes $\times 2$ dates) to generate a representative community composition and calculating the Bray-Curtis dissimilarity between the colonists and each treatment replicate on every date. Finally, we subtracted the BrayCurtis dissimilarity measure from 1 , so that 0 equals complete dissimilarity and 1 equals complete similarity.

\section{Statistical analyses}

We used two-way repeated measures analysis of variance (RM-ANOVA) to test for differences in total zooplankton abundance, species richness, similarity, and chl $a$ in dispersal and invasion treatments from week 1 through 5. We used a Tukey honestly significant difference post hoc test to examine significant differences between treatments. The Huynh-Feldt adjusted $P$ value is reported when repeated measures tests violate the assumption of sphericity, i.e., the differences between all pairs of treatments have equal variance. Separate ANOVAs were performed on week 0 samples to test for initial differences in zooplankton communities. By design, there were significant differences in some measures of zooplankton community structure and species abundances on week 0 (see Table 1). When treatments were significantly different on the initial sampling date, treatment interactions with time (e.g., time $\times$ invasion) were used to interpret the main effect of the treatment, using linear contrasts (Quinn and Keough 2002). Zooplankton community abundance, species richness, and edible chl $a$ were log-transformed prior to analysis to meet assumptions of normality and homoscedasticity. ANOVA and RM-ANOVA tests were performed using Statistica version 6 (StatSoft 2001).

We used principal components analysis (PCA) to analyze changes in community composition, as linear techniques are appropriate when the change in community composition across the underlying environmental gradient is less than three units (Lepš and Šmilauer 2003). Species abundances were Hellinger-transformed to reduce the influence of rare species (Legendre and Gallagher 2001), and a few extremely rare species were also removed (i.e., when occurrence was $<5 \%$ and when percent of total abundance was $<0.02 \%$ ). CANOCO 4.5 was used to perform the ordination (ter Braak and Šmilauer 2002), and site scores were averaged between replicates to generate the ordination diagram. Differences in community composition as measured by PCA were tested using a two-way RM-ANOVA on axis 1 site scores from individual enclosures from week 1 through 5 of the experiment, as well as two-way ANOVAs on the initial and final dates.

\section{RESUlTS}

Dispersal significantly increased zooplankton abundance, richness, and similarity to the regional colonist pool, but generally had the greatest effect in the invader- 
TABle 1. Extended.

\begin{tabular}{|c|c|c|c|c|c|}
\hline \multicolumn{2}{|c|}{$\begin{array}{c}\text { Large } \\
\text { cladocerans } \dagger\end{array}$} & \multicolumn{2}{|c|}{$\begin{array}{c}\text { Small } \\
\text { cladocerans } \dagger\end{array}$} & \multicolumn{2}{|c|}{$\mathrm{PCI} \dagger$} \\
\hline$F$ & $P$ & $F$ & $P$ & $F$ & $P$ \\
\hline 49.83 & $<0.01$ & 63.19 & $<0.01$ & 171.38 & $<0.01$ \\
\hline 26.31 & $<0.01$ & 13.14 & $<0.01$ & 28.09 & $<0.01$ \\
\hline 6.39 & $<0.01$ & 3.79 & 0.04 & 8.30 & $<0.01$ \\
\hline 55.51 & $<0.01$ & 54.32 & $<0.01$ & 123.81 & $<0.01$ \\
\hline 249.44 & $<0.01$ & 83.91 & $<0.01$ & 222.72 & $<\mathbf{0 . 0 1}$ \\
\hline 5.90 & $<0.01$ & 1.18 & 0.32 & 11.19 & $<0.01$ \\
\hline 2.51 & 0.02 & 0.60 & 0.77 & 1.78 & 0.10 \\
\hline
\end{tabular}

removed treatment, and relatively minor effects in the other invasion treatments (Fig. 1, Table 1). Dispersal significantly increased zooplankton abundance in the invader-removed treatment (Tukey $P<0.05$ ); however, dispersal had no effect in the invaded treatment or the never-invaded treatment (Tukey $P>0.05$; Fig. 1, Table 1). Within each dispersal treatment, zooplankton abundance was significantly lower when Bythotrephes was present (invaded treatment) compared to when it was absent (invader-removed and never-invaded treatments: Tukey $P<0.05$; Fig. 1, Table 1). There were significant time $\times$ invasion interactions in zooplankton abundance: abundance increased in the invader-removed treatment, but remained relatively constant in the invaded and never-invaded treatments (Fig. 1, Table 1).

While richness was significantly greater with dispersal in the invader and invader-removed treatments (Tukey $P<0.05)$, dispersal had no effect on richness in the never-invaded treatment (Tukey $P>0.05$; Fig. 1, Table 1). Within dispersal treatments, richness was significantly greater in the never-invaded treatment compared to the invaded treatment (Tukey $P<0.05$ ), but there was no difference between invaded and invader-removed richness (Tukey $P>0.05$; Fig. 1, Table 1). Invaderremoved zooplankton richness was significantly lower than never-invaded zooplankton richness in the no dispersal treatment (Tukey $P<0.05$ ), but there was no difference between invader-removed and never-invaded treatments with dispersal (Tukey $P>0.05$; Fig. 1, Table 1). Linear contrasts indicated that there was an invasion
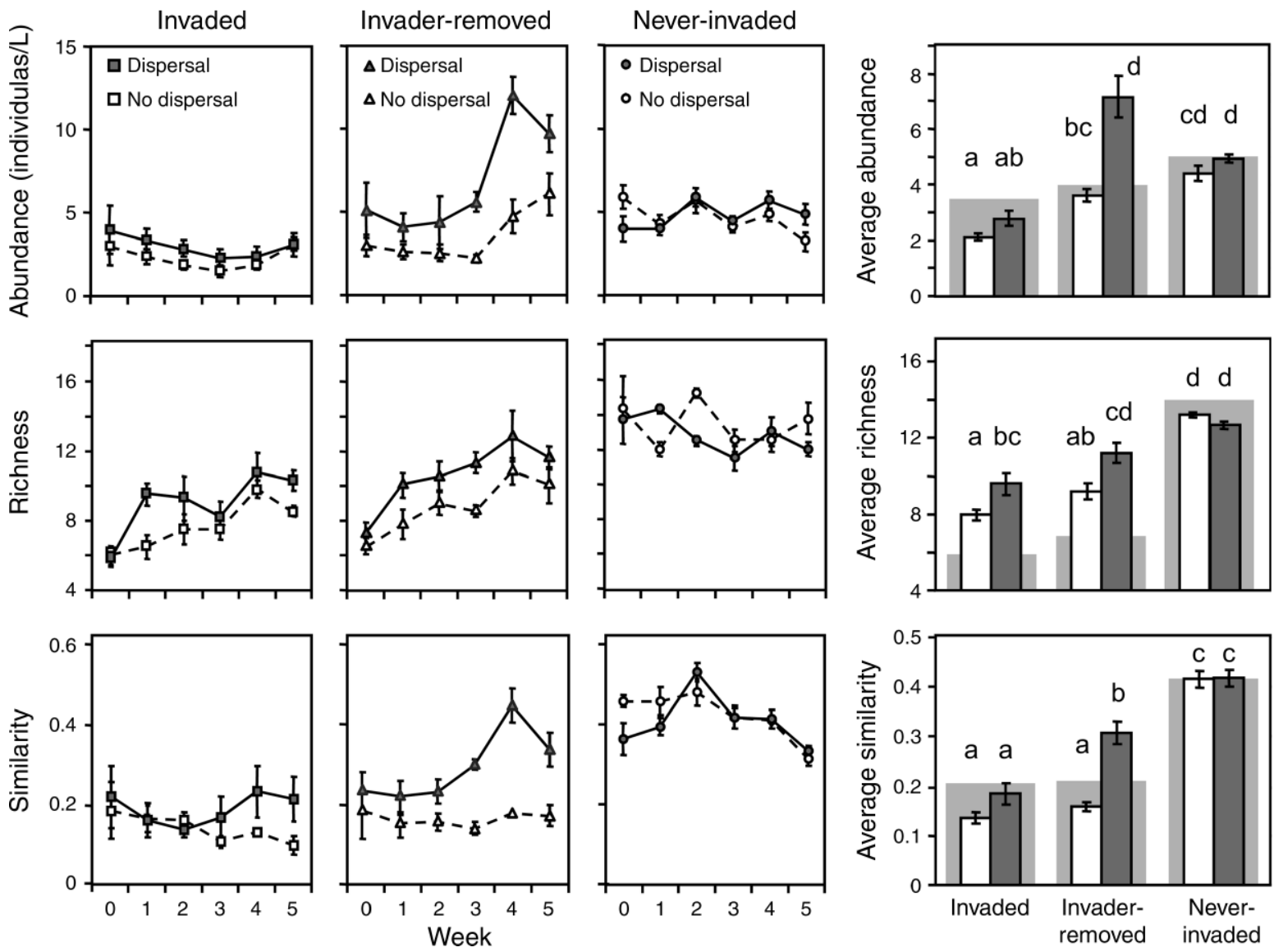

FIG. 1. Abundance (individuals/L), species richness, and similarity of zooplankton communities in invaded (squares), invaderremoved (triangles), and never-invaded (circles) treatments (solid = dispersal, open $=$ no dispersal). On the right, the average of community metrics over the final five weeks of the experiment is shown in the foreground, while light gray boxes in the background indicate the average of the initial week of the treatment. Letters above groups of treatments indicate significant differences $(P<$ 0.05 ) between treatment combinations using a Tukey post hoc test. Error bars represent \pm SE. 

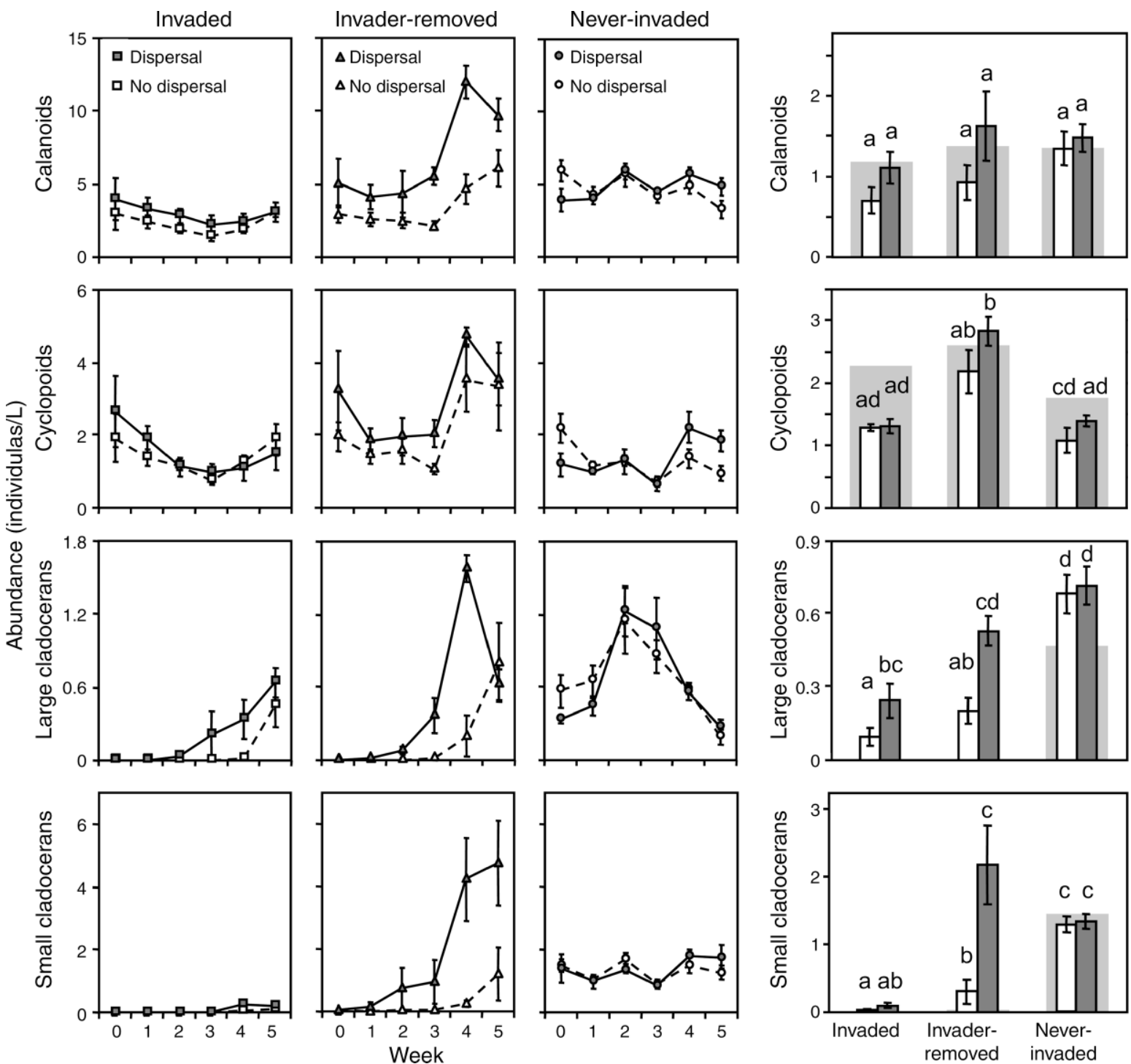

FIG. 2. Abundance (individuals/L) of calanoid, cyclopoid, large cladoceran, and small cladoceran functional groups in invaded (squares), invader-removed (triangles), and never-invaded (circles) treatments (solid, dispersal; open, no dispersal). On the right, the average of functional group abundances over the final five weeks of the experiment is shown in the foreground, while light gray boxes in the background indicate the average of the initial week of the treatment. Note difference in $y$-axis scales. Letters, shading, and error bars as in Fig. 1.

effect on species richness throughout the experiment, as richness increased in the invaded and invader-removed treatments, but did not change in the never-invaded treatment (time $\times$ invasion $P<0.01$; Fig. 1, Table 1).

Dispersal significantly increased the similarity of invader-removed zooplankton to the regional colonist pool compared to both the no dispersal treatment and the invaded treatment (Tukey $P<0.05$ ), but failed to achieve levels of similarity observed in the never-invaded community (Tukey $P<0.05$; Fig. 1, Table 1 ). The never-invaded treatment was more similar to the regional colonist pool at the start of the experiment compared to invaded and invader-removed treatments, and this trend continued throughout the experiment in both dispersal and no-dispersal treatments (Tukey $P<$ 0.05; Fig. 1, Table 1). Dispersal had no effect in the never-invaded and invaded treatments (Tukey $P>0.05$; Fig. 1, Table 1).

At the functional group level, the effects of dispersal were primarily observed in the cladocerans (Fig. 2, Table 1). Dispersal had moderate positive effects on calanoid $(P=0.08)$ and cyclopoid $(P=0.07)$ copepod abundance (Fig. 2, Table 1). There were no major differences in the abundance of calanoid copepods across invasion treatments (Tukey $P>0.05$ ); however, cyclopoid copepods were significantly more abundant in 
the dispersal invader-removed treatment compared to the dispersal invaded and the dispersal never-invaded treatments (Tukey $P<0.05$; Fig. 2, Table 1). There was no difference in cyclopoid copepod abundance between invaded and never-invaded treatments in both dispersal and no-dispersal treatments (Tukey $P>0.05$; Fig. 2, Table 1).

Dispersal increased the abundance of large cladocerans in the invaded and invader-removed treatments (Tukey $P<0.05$ ), but had no effect in the never-invaded treatment (Tukey $P>0.05$; Fig. 2, Table 1). Within dispersal treatments, there were significantly greater numbers of large cladocerans in the never-invaded treatment compared to the invaded treatment (Tukey $P>0.05)$, but no difference between invaded and invader-removed treatments (Tukey $P>0.05$; Fig. 2, Table 1). Small cladoceran abundance was significantly greater in the invader-removed treatment with dispersers added (Tukey $P<0.05$ ), but was unaffected in the invaded or never-invaded treatment (Tukey $P>0.05$; Fig. 2, Table 1). There were significant differences in small cladoceran abundance across the invasion treatments: with dispersal, invaded was less abundant than invader-removed and never-invaded (Tukey $P<0.05$ ), with no difference between invader-removed and neverinvaded (Tukey $P>0.05$ ), while in the no dispersal treatment, invaded was less abundant than invaderremoved (Tukey $P<0.05$ ), and both were less abundant than the never-invaded treatment (Tukey $P<0.05$; Fig. 2 , Table 1). Linear contrasts indicated that there was an invasion effect on large and small cladoceran abundance through the experiment, such that cladocerans increased through time in the invaded and invader-removed treatment, but either stayed constant (small cladocerans) or increased slightly (large cladocerans) in the neverinvaded treatment (time $\times$ invasion for both groups, $P<$ 0.01; Fig. 2, Table 1). Large cladocerans also displayed significant time $\times$ dispersal and time $x$ invasion $\times$ dispersal effects, where dispersal tended to increase large cladoceran abundance in the invaded and invaderremoved treatments, but had no effect in the neverinvaded treatment (Fig. 2, Table 1).

Zooplankton community composition of invaded and invader-removed treatments became more similar to never-invaded communities with immigration of regional colonists (Fig. 3). Principal component 1 (PC1) represents initial differences in community composition between never-invaded and invaded/invader-removed zooplankton communities. Never-invaded communities tended to be dominated by a diversity of cladoceran and copepod taxa, and were significantly different from invaded and invader-removed communities at the beginning of the experiment, which were composed primarily of copepods ( $\mathrm{PC} 1$ site scores, $F_{2,17}=325.06$, Tukey $P<0.05$, treatment standard error $0.02-0.14)$. There were significant changes in community composition over the course of the experiment for both dispersal and invasion treatments (time $x$ invasion and time $\times$ dispersal $P<0.01$, treatment standard error $0.03-0.31$ ). Overall, there was a significant interaction between invasion and dispersal: dispersal had no effect in the never-invaded community, but significantly changed the composition of the invaded and invader-removed communities compared to the no dispersal treatments (Fig. 3, Table 1). Additionally, in the presence of dispersers, invaded and invader-removed treatments were no longer significantly different from neverinvaded treatments on the final date of the experiment along PC1 (Tukey $P>0.05$; Fig. 3). This was likely due to the successful establishment of Bosmina spp. and Holopedium gibberum in the dispersal treatments, as these taxa were dominant in the never-invaded community. In the no-dispersal invaded treatment, large-bodied species that can avoid predation, such as Sida crystallina and Diacyclops bicuspidatus thomasi, were favored, while the fast-reproducing Eubosmina tubicen succeeded in the no dispersal invader-removed treatment, as well as the aforementioned large-bodied species.

Live Bythotrephes individuals were recovered during routine sampling from all of the invaded enclosures. On two dates, we sampled specifically for Bythotrephes using a larger net (diameter $0.5 \mathrm{~m}$ ) and found live individuals in seven of eight enclosures, though at lower densities $\left(<3\right.$ individuals $\left./ \mathrm{m}^{3}\right)$ than had been added. However, these densities are still within the range observed naturally in inland lakes (Yan et al. 2001).

\section{Discussion}

We found that dispersal of native taxa, especially in communities that have been structured by an invader, plays an important role in influencing zooplankton communities. Dispersal increased community abundance, species richness, similarity to the regional colonist pool, and abundance of some functional groups (Figs. 1, 2). As we predicted, the greatest establishment of colonists was in the invader-removed treatment, resulting in zooplankton community abundance and richness that was not statistically different from the never-invaded community. By the end of the experiment, community composition of the invaded and invaderremoved treatments with dispersal was no different from a never-invaded zooplankton community along principal component axis 1 (Fig. 3). This suggests that in general the local community in invaded and invaderremoved treatments had low resistance to colonizing species. Thus, dispersal may play an important role in structuring the zooplankton community in lakes invaded by Bythotrephes by supplying propagules of functional groups that tend to be reduced, such as large and small cladocerans (Fig. 2). Additionally, dispersal significantly increased species richness in the invaded treatment, to the extent that both invaded and invader-removed communities had roughly equal numbers of species. However, this likely reflects establishment by few individuals, as evenness of the invaded community remained low (Strecker 2007), suggesting that loss of 

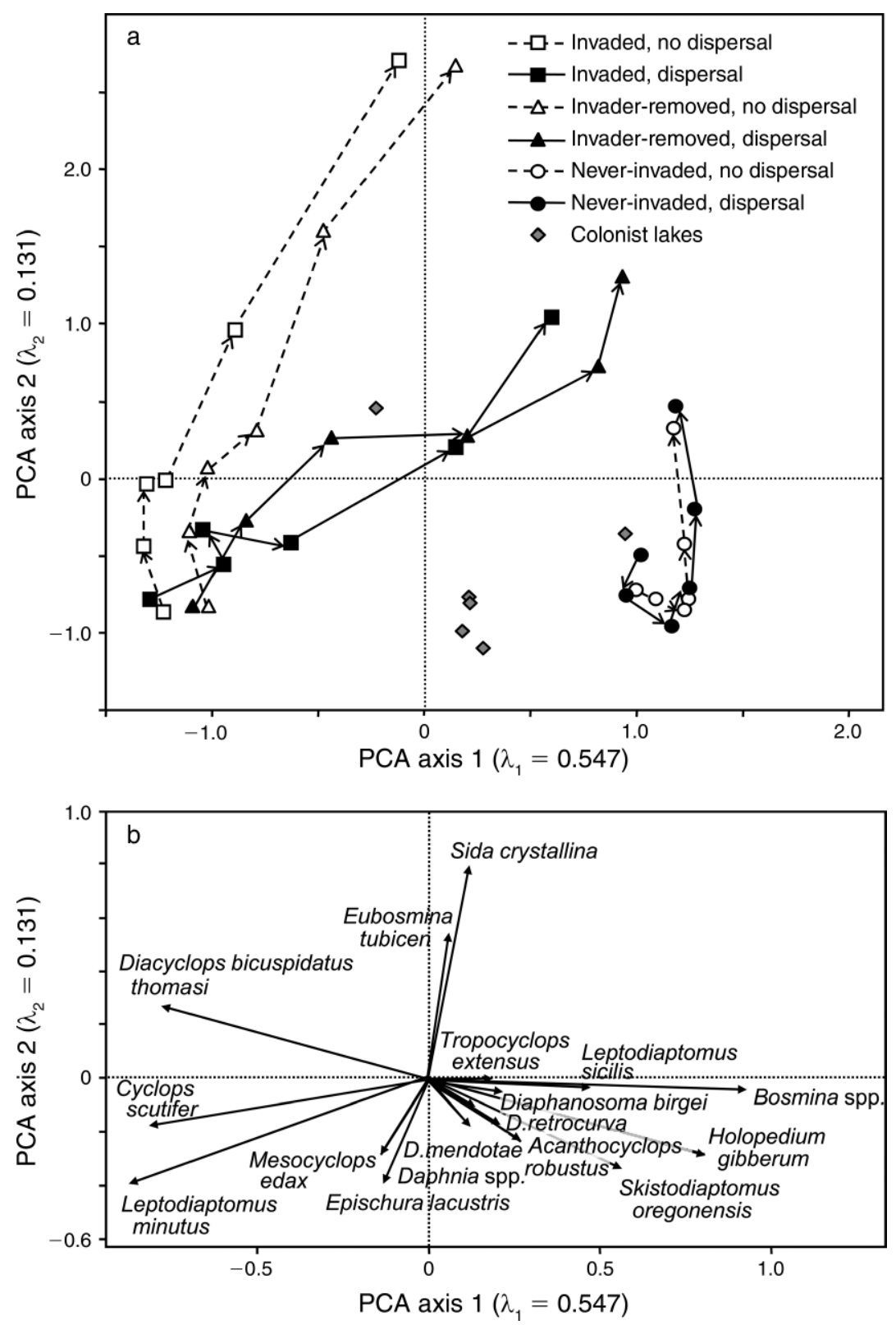

FIG. 3. Principal components analysis of (a) site scores and (b) species scores. In panel (a), symbols represent the average of the invaded (squares), invader-removed (triangles), and never-invaded (circles) treatments, with black symbols representing dispersal, and white symbols no dispersal. For comparison, colonist lake site scores from both dates are plotted with gray diamonds. The direction of the arrows indicates the progression of the experiment, from week 0 to week 6.

diversity following the invasion of Bythotrephes may be permanent.

Our results suggest that the ability of colonists to establish and have an influence on community structure is highly context-dependent. In the never-invaded community, we hypothesized that the local community would prevent new species from colonizing by effectively monopolizing available resources (MacArthur and Levins 1967, De Meester et al. 2002). Indeed, local biotic factors seem to have exerted a strong influence on species establishment, such that dispersal had no effect on zooplankton abundance, richness, or composition. This supports the results of several studies that have found that zooplankton communities are saturated and will resist colonization by dispersers (Shurin 2000, Forrest and Arnott 2006). Additionally, dispersal had only moderate effects on zooplankton abundance in the invaded treatment, supporting our hypothesis that establishment would generally be poor in the presence of the predator. However, dispersal significantly increased zooplankton abundance in the invader-removed community, in agreement with the view that dispersal is 
limiting (Cornell and Lawton 1992, Gilbert and Lechowicz 2004), especially when communities have been structured by disturbance (Seabloom et al. 2003). The establishment of cladoceran functional groups in the invader-removed dispersal treatment likely reflects differential resource use compared to the resident community (MacArthur and Levins 1967). Cladocerans were virtually absent from invaded and invaderremoved treatments at the start of the experiment; however, dispersal facilitated the establishment of those species able to fill niches made empty by predation. Tilman (1997) also observed differential establishment of grassland plant functional groups, which he attributed to the joint effects of local conditions and the traits of the resident community. Our results also concur with the seed addition experiment of MacDougall and Wilson (2007): strong herbivory prevented seedling establishment in most treatments, whereas competition with herbivore-tolerant or resistant species prevented establishment in no herbivore treatments. Thus, strong local interactions, such as predation or interspecific competition for resources, may effectively close a community to immigration, but in the absence of these strong interactions, immigrating species may establish. Indeed, there is theoretical evidence that species can colonize systems with relatively weak trophic interaction strengths (Maser et al. 2007).

In communities where colonization was successful (i.e., invader-removed and to a lesser extent, invaded), the species that established can be characterized by several general attributes.

1) Rapid population growth. Several cladoceran taxa, including small-bodied bosminids and the large-bodied Holopedium gibberum, established in significant numbers in invader-removed treatments (Appendix B). Cladoceran life history strategies are characterized by rapid maturation and short generation times, which allow for high intrinsic growth rates (Allan and Goulden 1980). Thus, the ability to quickly increase population size is likely a key characteristic influencing colonization success.

2) Morphological adaptations to predation. In invaded treatments, the relatively large-bodied $H$. gibberum and Skistodiaptomus oregonensis were successful colonists (Appendix B). Additionally, H. gibberum produces a large gelatinous sheath, which can provide some protection from predation (Zaret 1980). Howeth and Leibold (2008) found that species possessing predator tolerance or avoidance mechanisms were successful colonists in a zooplankton metacommunity subject to fluctuating predation pressure. Thus, the ability to attain large body sizes or produce anti-predator morphologies to reduce predation are traits that likely favor establishment of dispersers.

3) Timing. The timing of dispersal may have a significant influence on colonist establishment. For example, although copepods have substantially longer development times compared to cladocerans, they are capable of producing large clutches of eggs in short succession and cohorts can develop synchronously (Allan and Goulden 1980), which suggests that Allee effects will be reduced as individuals mature at roughly the same time. Jenkins and Buikema (1998) observed rapid colonization of several copepod species in their experimental ponds, which they attributed to synchronous hatching of nauplii. This suggests that favorable timing of dispersal (e.g., when populations have reached maturity or are at high abundance) may also influence colonist establishment.

It is of interest to note that the only species to establish in significant numbers in both invaded and invader-removed treatments, $H$. gibberum, was also the only species that combined all three of the aforementioned characteristics: rapid growth rates, morphological adaptations to predation, and timing (H. gibberum was relatively abundant when colonists were experimentally added to enclosures, comprising $15 \%$ of the regional colonist pool; Appendix B). Therefore, the establishment of colonists may be determined by a combination of life history, morphology, and chance events.

Dispersal may have significant effects on community structure and composition during periods of transient fluctuations in species abundances. Wright (2008) showed that an invader can cause transient crashes in prey populations in a closed system, particularly for species vulnerable to the invader. At the beginning of our experiment, prey species that are known to be vulnerable to Bythotrephes were effectively in the crash phase of this nonequilibrium state: cladocerans were virtually absent from the invader-removed treatment (Fig. 2). We predicted that (1) colonists would have the greatest establishment and therefore greatest influence on community structure and composition in the invaderremoved treatment and (2) dispersal would accelerate the return of vulnerable species, particularly those that have rapid growth rates, as predation on these species would be absent in the invader-removed treatment. As expected, we found that dispersal had the greatest effect on community abundance, richness, and composition in the invader-removed treatment (Figs. 1 and 3). Surprisingly, a predation-resistant species and several vulnerable species successfully established in the invader-removed zooplankton community (Appendix B). Predator resistance by means of life history or morphological adaptations typically comes at a cost: species trade off their competitive ability for tolerance of the environmental conditions. In a stable environment, the better competitors tend to exclude the stress-tolerant species, but in a fluctuating environment, competitive exclusion does not proceed, promoting species coexistence (Chesson 2000, Chase and Leibold 2003). Thus, the establishment of predation-resistant species in the absence of a predator may reflect a sort of metacommunity bet hedging strategy against future fluctuations in the environment (Cohen 1966), in this case, the 
expected presence of a predator. We hypothesize that had our experiment continued for a longer time period and barring other physical and chemical changes, this trade-off may be reversed in invader-removed treatments, as specific anti-predator adaptations would no longer be favored and species with these traits would be replaced by better competitors in a stable environment. Indeed, predation-resistant $H$. gibberum was beginning to decline over the final week of the experiment in the invader-removed treatment, while smaller vulnerable bosminids were increasing (A. Strecker, unpublished data). Additionally, richness was also declining at the end of the experiment in the invader-removed treatment, suggesting that competition between these species may have been occurring and reducing the potential for coexistence. Thus, dispersal can have a significant role in shaping the composition of communities that are in transition, as the maintenance of trait variation in a metacommunity ensures that there are some species that are better suited to the changing environmental conditions (Howeth and Leibold 2008) and can track these fluctuations via a species-sorting mechanism (Leibold et al. 2004).

Our experiment demonstrates the importance of dispersal in altering the structure and composition of a community during a period of transient-prey response dynamics on a short time scale. In contrast, the absence of dispersal may slow community responses to a change in the environment. The invader-removed community began to respond to a relaxation of predation pressure at the conclusion of the experiment in the absence of dispersal: several zooplankton functional groups increased in abundance over the final two weeks of the experiment (Fig. 2). However, the response was considerably delayed and weaker in magnitude compared to the dispersal treatment. This implies that invaded communities have poor resiliency, and are limited in their ability to quickly respond to changes in the biotic environment without dispersal from the region. Dispersal may accelerate adaptation to invasion, as genetic and species variation can be augmented by the addition of regional colonists in the face of declines associated with the introduction of invasive species. Thus, dispersal may better enable communities to track changing environmental conditions as a complex adaptive system (Leibold and Norberg 2004).

\section{Implications}

Regions will differ in the degree of connectedness between local habitats, depending on landscape features such as the density of lakes, stream connections, and elevation. Our manipulation is a realistic simulation of levels of dispersal that have been observed in interconnected pond systems (Michels et al. 2001). Thus, we might expect that the significant effect of dispersal on invaded community structure that we observed would also be observed in regions with similarly high levels of dispersal. Beisner et al. (2006) demonstrated that dispersal via both overland and watercourse pathways between lakes had significant effects on zooplankton community structure. Additionally, for a number of terrestrial and aquatic organisms, dispersal can occur from a reservoir of dormant life-stages (e.g., a seed bank in plants, a resting egg bank in freshwater zooplankton). The hatching of these dormant stages enables some species to take advantage of fluctuating environmental conditions via a mechanism known as the storage effect (Chesson 1994), allowing species and genetic variation to be reintroduced into the system (Urban and Skelly 2006). Although we did not explicitly consider the egg bank in this experiment, resting eggs can provide a wealth of biotic and genetic resilience to stress (Hairston 1996), enabling zooplankton to adaptively respond to environmental fluctuations, such as changes in predation pressure (Cousyn et al. 2001). Hence, both dispersal through space and time are strategies that may frequently co-occur in local communities (Eriksson 1996) and may be particularly important during environmental fluctuations, as an influx of propagules to systems via both mechanisms may significantly alter community structure (Arnott et al. 2001, Arnott and Yan 2002).

In contrast, the effects of invasion on native species may be exacerbated in fragmented habitats in both aquatic and terrestrial systems where dispersal is low. In invaded systems, native species that are negatively affected by invasion may exist as low abundance population sinks, relying on dispersal to maintain population persistence. When dispersal is reduced as a result of fragmentation, the persistence of these sink populations may also decline. Additionally, even if colonists are able to disperse to the invaded habitat from a source population that remains on the landscape, sink populations may be less able to adapt to the invader if the source populations have not been invaded (With 2002). Uninvaded source populations would likely have differing selective pressures, which would dilute the response of the sink population to the invader (With 2002). However, dispersal can also occur from a source population that has been invaded for a sufficient length of time for adaptation to occur, as the species that remain would be the best adapted to coexist with the invader, accelerating the adaptive response of some sink populations in a newly invaded system. Conversely, successful invaders are characteristically thought to have superior dispersal abilities (Moyle 1986, Lodge 1993), and therefore may be less affected by habitat fragmentation compared to native species. The ability of invaders to adapt to the new environment may be enhanced if there are multiple introductions from diverse sites, bringing greater genetic diversity (e.g., Lavergne and Molofsky 2007). Thus, habitat fragmentation may result in reduced dispersal frequency and lowered potential for adaptation in native species, but also greater potential for adaptation in invaders, which 
may act synergistically to intensify declines in native species that result from invasive species introductions.

Finally, spatial correlation in patterns of invasion may play a role in the ability of a community to act as a complex adaptive system. Matthews and Gonzalez (2007) experimentally observed reduced persistence of sink metapopulations when fluctuations in environmental variables were correlated across patches, which increased synchrony among populations. Synchronous changes within a metapopulation can increase the risk of species extinction (Heino et al. 1997), as there is a greater probability of chance events driving populations to zero, thereby reducing the potential for recolonization (Harrison and Quinn 1989). This reduction in persistence of sink metapopulations occurred despite substantial dispersal from other patches in the metapopulation (Matthews and Gonzalez 2007). These results may have important implications for our understanding of the effects of invasive species in their introduced range. Using the invasion of Bythotrephes in the Great Lakes region as a case study, there are a relatively large number of invaded lakes in a region where systems are connected by rivers and streams (i.e., drainage lakes) and likely experience moderate levels of dispersal, suggesting that native species in this area can act as metapopulations. The presence of Bythotrephes in this area is likely spatially autocorrelated due to humanmediated vectors of invasion, i.e., lakes in close proximity are more likely to be invaded (MacIsaac et al. 2004). Thus, the invasion of Bythotrephes may increase the probability of local species extinctions, as dispersal becomes a less effective agent of community rescue of sink populations in spatially autocorrelated landscapes of invasion. This may be a mechanism for the wide-spread decline in occurrence of species across the landscape that has been observed following the invasion of Bythotrephes in North American (Boudreau and Yan 2003, Strecker et al. 2006). In a more general sense, this suggests that invasive species may be a type of spatially autocorrelated environmental variation (e.g., climate; Peltonen et al. 2002), and need to be considered within the broader context of the landscape in order to gain a better understanding of the consequences of invasion.

The invasion of species outside their native range can have detrimental effects on ecosystems (Carlsson et al. 2004), and are a growing concern because of the increased rates of species invasions with human activity (Vitousek et al. 1997). We have experimentally demonstrated that, in the presence of dispersal, invaded zooplankton communities are resilient and can recover quickly when a predator is removed. Establishment of regional colonists during periods of transient community dynamics may generate "rescue effects" by supplying species and functional groups with adaptive life history and morphological traits. It is likely that the number of lakes invaded by Bythotrephes will grow in the future because they are primarily dispersed by human vectors (MacIsaac et al. 2004), thus dispersal of regional colonists may play a role in mediating the effects of the invader on native species in the years to come.

\section{AcKnowledgments}

We thank A. Derry, J. Forrest, M. Cuke, A. Kalyniuk, and M. Neytcheva for their hard work on this project. We also thank J. Forrest, K. Samis, A. Jokela, D. Gray, and two anonymous reviewers for their insightful comments. We are grateful to the staff of the Cooperative Freshwater Ecology Unit, the Ontario Ministry of the Environment, and Killarney Provincial Park for providing equipment, logistical support, and water chemistry analysis. Funding was provided by an NSERC Discovery Grant (to S. E. Arnott) and Post-Graduate Scholarship (to A. L. Strecker), as well as an Ontario Graduate Scholarship in Science and Technology, the Ontario Federation of Anglers and Hunters, and a Queen's University Graduate Dean's Travel Grant.

\section{Literature Cited}

Allan, J. D., and C. E. Goulden. 1980. Some aspects of reproductive variation among freshwater zooplankton. Pages 388-410 in W. C. Kerfoot, editor. Evolution and ecology of zooplankton communities. University Press of New England, Hanover, New Hampshire, USA.

Arnott, S. E., and N. Yan. 2002. The influence of drought and re-acidification on zooplankton emergence from resting stages. Ecological Applications 12:138-153.

Arnott, S. E., N. D. Yan, W. Keller, and K. Nicholls. 2001. The influence of drought-induced acidification on the recovery of plankton in Swan Lake (Canada). Ecological Applications 11:747-763.

Beisner, B. E., P. R. Peres-Neto, E. S. Lindström, A. Barnett, and M. L. Longhi. 2006. The role of environmental and spatial processes in structuring lake communities from bacteria to fish. Ecology 87:2985-2991.

Boudreau, S. A., and N. D. Yan. 2003. The differing crustacean zooplankton communities of Canadian Shield lakes with and without the nonindigenous zooplanktivore Bythotrephes longimanus. Canadian Journal of Fisheries and Aquatic Sciences 60:1307-1313.

Branstrator, D. K., M. E. Brown, L. J. Shannon, M. Thabes, and K. Heimgartner. 2006. Range expansion of Bythotrephes longimanus in North America: evaluating habitat characteristics in the spread of an exotic zooplankter. Biological Invasions 8:1367-1379.

Brown, J. H., and A. Kodric-Brown. 1977. Turnover rates in insular biogeography: effect of immigration on extinction. Ecology 58:445-449.

Cadotte, M. W. 2006. Dispersal and species diversity: a metaanalysis. American Naturalist 167:913-924.

Cadotte, M. W., A. M. Fortner, and T. Fukami. 2006. The effects of resource enrichment, dispersal, and predation on local and metacommunity structure. Oecologia 149:150-157.

Carlsson, N. O. L., C. Brönmark, and L.-A. Hansson. 2004. Invading herbivory: the golden apple snail alters ecosystem functioning in Asian wetlands. Ecology 85:1575-1580.

Chase, J. M., and M. A. Leibold. 2003. Ecological niches: linking classical and contemporary approaches. University of Chicago Press, Chicago, Illinois, USA.

Chesson, P. 1994. Multispecies competition in variable environments. Theoretical Population Biology 45:227-276.

Chesson, P. 2000. Mechanisms of maintenance of species diversity. Annual Review of Ecology and Systematics 31: 343-366.

Chesson, P., and N. Huntly. 1997. The roles of harsh and fluctuating conditions in the dynamics of ecological communities. American Naturalist 150:519-553.

Cohen, D. 1966. Optimizing reproduction in a randomly varying environment. Journal of Theoretical Biology 12: $119-129$. 
Cornell, H. V., and J. H. Lawton. 1992. Species interactions, local and regional processes, and limits to the richness of ecological communities: a theoretical perspective. Journal of Animal Ecology 61:1-12.

Cottenie, K. 2005. Integrating environmental and spatial processes in ecological community dynamics. Ecology Letters 8:1175-1182.

Cousyn, C., L. De Meester, J. K. Colbourne, L. Brendonck, D. Verschuren, and F. Volckaert. 2001. Rapid, local adaptation of zooplankton behavior to changes in predation pressure in the absence of neutral genetic changes. Proceedings of the National Academy of Sciences (USA) 98:6256-6260.

Davis, M. A., J. P. Grime, and K. Thompson. 2000. Fluctuating resources in plant communities: a general theory of invasibility. Journal of Ecology 88:528-534.

De Meester, L., A. Gómez, B. Okamura, and K. Schwenk. 2002. The monopolization hypothesis and the dispersal-gene flow paradox in aquatic organisms. Acta Oecologica 23: 121-135.

Eriksson, O. 1996. Regional dynamics of plants: a review of evidence for remnant, source-sink and metapopulations. Oikos 77:248-258.

Forrest, J., and S. E. Arnott. 2006. Immigration and zooplankton community responses to nutrient enrichment: a mesocosm experiment. Oecologia 150:119-131.

Gilbert, B., and M. J. Lechowicz. 2004. Neutrality, niches, and dispersal in a temperate forest understory. Proceedings of the National Academy of Sciences (USA) 101:7651-7656.

Gonzalez, A., and R. D. Holt. 2002. The inflationary effects of environmental fluctuations in source-sink systems. Proceedings of the National Academy of Sciences (USA) 99:14872-14877.

Hairston, N. G., Jr. 1996. Zooplankton egg banks as biotic reservoirs in changing environments. Limnology and Oceanography 41:1087-1092.

Harrison, S., and J. F. Quinn. 1989. Correlated environments and the persistence of metapopulations. Oikos 56:293-298.

Hastings, A. 2004. Transients: the key to long-term ecological understanding? Trends in Ecology and Evolution 19:39-45.

Heino, M., V. Kaitala, E. Ranta, and J. Lindstrom. 1997. Synchronous dynamics and rates of extinction in spatially structured populations. Proceedings of the Royal Society B 264:481-486.

Holt, C., and N. Yan. 2003. Recovery of crustacean zooplankton communities from acidification in Killarney Park, Ontario, 1971-2000: pH 6 as a recovery goal. Ambio 32: 203-207.

Holt, R. D. 1985. Population dynamics in two-patch environments: some anomalous consequences of an optimal habitat distribution. Theoretical Population Biology 28:181-208.

Holyoak, M., M. A. Leibold, and R. D. Holt, editors. 2005. Metacommunities: spatial dynamics and ecological communities. University of Chicago Press, Chicago, Illinois, USA.

Howeth, J. G., and M. A. Leibold. 2008. Planktonic dispersal dampens temporal trophic cascades in pond metacommunities. Ecology Letters 11:245-257.

Huisman, J., and F. J. Weissing. 1999. Biodiversity of plankton by species oscillations and chaos. Nature 402:407-410.

Jenkins, D. G., and A. L. Buikema, Jr. 1998. Do similar communities develop in similar sites? A test with zooplankton structure and function. Ecological Monographs 68: $421-443$.

Johannsson, O. E., E. L. Mills, and R. O'Gorman. 1991. Changes in the nearshore and offshore zooplankton communities in Lake Ontario: 1981-1988. Canadian Journal of Fisheries and Aquatic Sciences 48:1546-1557.

Keller, W., J. H. Heneberry, and S. S. Dixit. 2003. Decreased acid deposition and the chemical recovery of Killarney, Ontario lakes. Ambio 32:183-189.

Kneitel, J. M., and T. E. Miller. 2003. Dispersal rates affect species composition in metacommunities of Sarracenia purpurea inquilines. American Naturalist 162:165-171.
Lavergne, S., and J. Molofsky. 2007. Increased genetic variation and evolutionary potential drive the success of an invasive grass. Proceedings of the National Academy of Sciences (USA) 104:3883-3888.

Legendre, P., and E. D. Gallagher. 2001. Ecologically meaningful transformations for ordination of species data. Oecologia 129:271-280.

Leibold, M. A., M. Holyoak, N. Mouquet, P. Amarasekare, J. M. Chase, M. F. Hoopes, R. D. Holt, J. B. Shurin, R. Law, D. Tilman, M. Loreau, and A. Gonzalez. 2004. The metacommunity concept: a framework for multi-scale community ecology. Ecology Letters 7:601-613.

Leibold, M. A., and J. Norberg. 2004. Biodiversity in metacommunities: Plankton as complex adaptive systems? Limnology and Oceanography 49:1278-1289.

Lepš, J., and P. Šmilauer. 2003. Multivariate analysis of ecological data using CANOCO. Cambridge University Press, Cambridge, UK.

Lodge, D. M. 1993. Biological invasions: lessons for ecology. Trends in Ecology and Evolution 8:133-137.

MacArthur, R., and R. Levins. 1967. The limiting similarity, convergence and divergence of coexisting species. American Naturalist 101:377-385.

MacArthur, R. H., and E. O. Wilson. 1967. The theory of island biogeography. Princeton University Press, Princeton, New Jersey, USA.

MacDougall, A. S., and S. D. Wilson. 2007. Herbivory limits recruitment in an old-field seed addition experiment. Ecology 88:1105-1111.

MacIsaac, H. J., J. V. M. Borbely, J. Muirhead, and P. A. Graniero. 2004. Backcasting and forecasting biological invasions of inland lakes. Ecological Applications 14:773783.

Maser, G. L., F. Guichard, and K. McCann. 2007. Weak trophic interactions and the balance of enriched metacommunities. Journal of Theoretical Biology 247:337-345.

Matthews, D. P., and A. Gonzalez. 2007. The inflationary effects of environmental fluctuations ensure the persistence of sink metapopulations. Ecology 88:2848-2856.

McPeek, M. 1998. The consequences of changing the top predator in a food web: a comparative experimental approach. Ecological Monographs 68:1-23.

Michels, E., K. Cottenie, L. Neys, and L. De Meester. 2001. Zooplankton on the move: first results on the quantification of dispersal of zooplankton in a set of interconnected ponds. Hydrobiologia 442:117-126.

Moyle, P. B. 1986. Fish introductions into North America: patterns and ecological impact. Pages $27-43$ in H. A. Mooney and J. A. Drake, editors. Ecology of biological invasions of North America and Hawaii. Springer-Verlag, New York, New York, USA.

Noonburg, E. G., and P. A. Abrams. 2005. Transient dynamics limit the effectiveness of keystone predation in bringing about coexistence. American Naturalist 165:322-335.

Paine, R. T. 1966. Food web complexity and species diversity. American Naturalist 100:65-75.

Peltonen, M., A. M. Liebhold, O. N. Bjørnstad, and D. W. Williams. 2002. Spatial synchrony in forest insect outbreaks: roles of regional stochasticity and dispersal. Ecology 83: $3120-3129$.

Proulx, M., and A. Mazumder. 1998. Reversal of grazing impact on plant species richness in nutrient-poor vs. nutrient rich ecosystems. Ecology 79:2581-2592.

Quinn, G. P., and M. J. Keough. 2002. Experimental design and data analysis for biologists. Cambridge University Press, Cambridge, UK.

Sala, O., et al. 2000. Global biodiversity scenarios for the year 2100. Science 287:1770-1774.

Seabloom, E. W., W. S. Harpole, O. J. Reichman, and D. Tilman. 2003. Invasion, competitive dominance, and resource use by exotic and native California grassland species. 
Proceedings of the National Academy of Sciences (USA) 100: 13384-13389.

Shmida, A., and M. V. Wilson. 1985. Biological determinants of species diversity. Journal of Biogeography 12:1-20.

Shurin, J. B. 2000. Dispersal limitation, invasion resistance, and the structure of pond zooplankton communities. Ecology 81: 3074-3086.

Shurin, J. B. 2001. Interactive effects of predation and dispersal on zooplankton communities. Ecology 82:3404-3416.

Shurin, J. B., J. E. Havel, M. A. Leibold, and B. Pinel-Alloul. 2000. Local and regional zooplankton species richness: a scale-independent test for saturation. Ecology 81:3062-3073.

Simberloff, D., and L. Gibbons. 2004. Now you see them, now you don't: population crashes of established introduced species. Biological Invasions 6:161-172.

Sprules, W. G. 1977. Crustacean zooplankton communities as indicators of limnological conditions: an approach using principal components analysis. Journal of the Fisheries Research Board of Canada 34:962-975.

StatSoft. 2001. STATISTICA 6. StatSoft Inc., Tulsa, Oklahoma, USA.

Strecker, A. L. 2007. Responses of zooplankton community structure and ecosystem function to the invasion of an invertebrate predator, Bythotrephes longimanus. Dissertation. Queen's University, Kingston, Ontario, Canada.

Strecker, A. L., and S. E. Arnott. 2008. Invasive predator, Bythotrephes, has varied effects on ecosystem function in freshwater lakes. Ecosystems 11:490-503.

Strecker, A. L., S. E. Arnott, N. D. Yan, and R. Girard. 2006. Variation in the response of crustacean zooplankton species richness and composition to the invasive predator Bythotrephes longimanus. Canadian Journal of Fisheries and Aquatic Sciences 63:2126-2136.

ter Braak, C. J. F., and P. Šmilauer. 2002. CANOCO Version 4.5. Biometris-Plant Research International, Wageningen, The Netherlands.
Tilman, D. 1997. Community invasibility, recruitment limitation, and grassland biodiversity. Ecology 78:81-92.

Urban, M. C., and D. K. Skelly. 2006. Evolving metacommunities: toward an evolutionary perspective on metacommunities. Ecology 87:1616-1626.

Vanderploeg, H. A., J. R. Liebig, and M. Omair. 1993. Bythotrephes predation on Great Lakes' zooplankton measured by an in situ method: implications for zooplankton community structure. Archiv für Hydrobiologie 127:1-8.

Vitousek, P. M., H. A. Mooney, J. Lubchenco, and J. M. Melillo. 1997. Human domination of Earth's ecosystems. Science 277:494-499.

Warren, P. H., R. Law, and A. J. Weatherby. 2003. Mapping the assembly of protist communities in microcosms. Ecology 84:1001-1011.

With, K. A. 2002. The landscape ecology of invasive spread. Conservation Biology 16:1192-1203.

Wright, R. W. 2008. The geometry of transient crashes and their dependence on demographic rates. Theoretical Population Biology 73:300-306.

Yan, N. D., A. Blukacz, W. G. Sprules, P. K. Kindy, D. Hackett, R. E. Girard, and B. J. Clark. 2001. Changes in zooplankton and the phenology of the spiny water flea, Bythotrephes, following its invasion of Harp Lake, Ontario, Canada. Canadian Journal of Fisheries and Aquatic Sciences 58:2341-2350.

Yan, N. D., R. E. Girard, and S. Boudreau. 2002. An introduced invertebrate predator (Bythotrephes) reduces zooplankton species richness. Ecology Letters 5:481-485.

Young, J. D. 2008. Ecological regulators of the life history, morphology, behaviour and abundance of the invasive zooplanktivore Bythotrephes longimanus in south-central Ontario lakes. Dissertation. York University, Toronto, Ontario.

Zaret, T. M. 1980. Predation and freshwater communities. Yale University Press, New Haven, Connecticut, USA.

APPENDIX A

Description of experimental lakes (Ecological Archives E091-073-A1).

\section{APPENDIX B}

Species abundances and colonist survival (Ecological Archives E091-073-A2).

\section{APPENDIX C}

Water chemistry and chlorophyll methods and results (Ecological Archives E091-073-A3). 